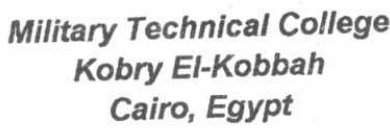

$10^{\text {th }}$ International Conference

On Aerospace Sciences\&

Aviation Technology

\title{
EXPERIMENTAL STUDY OF HEAT TRANSFER ENHANCEMENT WITH A SINGLE INCLINED PERFORATED OBSTACLE IN A RECTANGULAR CHANNEL
}

\author{
REDA I. AFIFY*
}

\section{ABSTRACT}

Measurements were carried out to investigate the enhancement in the heat transfer and the influence of flow friction in a rectangular channel using a single inclined perforated obstacle (baffle) affixed on the bottom surface which was heated with a uniform heat flux. A horizontal rectangular channel with an aspect ratio, height/width, of 1:5 was examined. The obstacle was attached to the heated surface and properly aligned in the favorable direction of the flow. Both solid (without perforation) and perforated obstacles were used. The effects of perforation, obstacle length, and gap between obstacle and upper surface were studied. The oper-area ratio $(\beta)$ of 0 , $0.023,0.038,0.115$, and 0.167 were investigated and Reynolds number ranged from 15000 to 45000 . The experiments covered a range of obstadle length to channel height ratio $(\mathrm{L} / \mathrm{H})$ from 2.0 to 6.0 , and gap to channel height ratio $(\mathrm{B} / \mathrm{H})$ from 0.3 to 0.7 . Inclined perforated obstacle combines three major heat transfer techniques, e.g. boundary layer separation, internal flow swirls, and jet impingement. The result showed that the maximum heat transfer enhancement and friction factor were about 3.7 and 11.0 times more than that smooth channel, respectively, and these of values were achieved using obstacle with $\beta=0.023, \mathrm{~L} / \mathrm{H}=2.0$, and $\mathrm{B} / \mathrm{H}=0.3$. The greatest efficiency index was found for the obstacle with $\beta=0.167, \mathrm{~L} / \mathrm{H}=6.0$, and $\mathrm{B} / \mathrm{H}=0.7$, where, a maximum efficiency index of about 1.6 was found. New correlations were obtained for the influence of the parameters on both Nusselt number enhancement and flow friction factor ratios.

\section{Key Words}

Heat transfer enhancement, inclined obstacle (baffle), perforated obstacle, rectangular channel flow. 


\section{NOMENCLATURE}

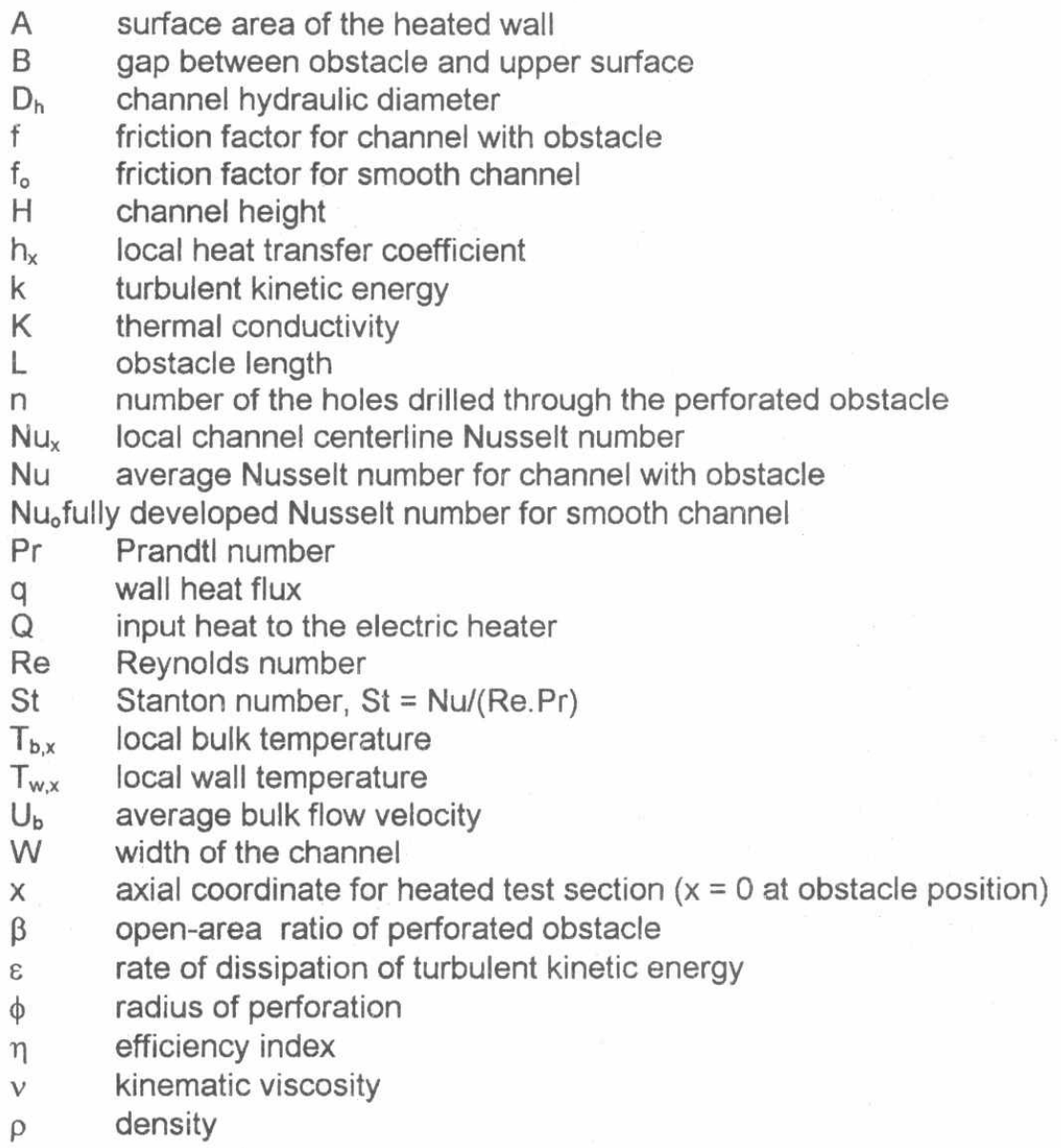

\section{INTRODUCTION}

The heat transfer coefficient of gases is low compared to that of liquids. The fundamental objective of this study is to improve the heat transfer behavior of a gaseous fluid in a channel by the placement of inclined perforated obstacles. Placement of obstacles or baffles on walls of a channel interrupts the development of the boundary layers and causes the flow to separate at the fixed edges, creating a recirculation zone downstream. The recirculating eddies carry the near-wall fluid to the edge of the core and then diffuse away the heat. Also, the separation caused by obstacles creates reversed-flow regions of high mixing and turbulence generation. Furthermore, the obstacles provide additional surface area for heat transfer. Applications of the inclined obstacles may be in the large land based gas turbine blade coolant path, air-cooled solar collectors, electronic cooling devices, compact heat exchangers, and power plants. To augment the heat transfer coefficient of gases in internal flow, the following techniques are generally used: (i) Boundary 
layer disturbance caused by periodically placed ribs on the heat transfer surface. These ribs are small and do not disturb the core flow and therefore, the turbulence enhancement and boundary layer break down are mostly localized near the heat transfer surface. Ribs provide excellent cooling enhancement with a comparatively low penalty in the pressure drop increase for low to moderate Reynolds numbers. (ii) Impingement cooling uses high velocity jets to cool the surface of interest. However, often a large region needs to be cooled and multiple jets are required. Multiple jets get deflected in the presence of cross flow developed by upstream spent-jets. (iii) The third technique is the use of internal flow swirls or tape twisters. This technique creates a significant amount of bulk flow disturbance, and pressure drop may be higher compared to the increase in heat transfer coefficient.

Inclined solid obstacles may be considered as a combination or ribs and channel inserts. The obstacles or baffles are big enough to disturb the core flow, but like ribs, they are mounted on or near the heat transfer surface and can periodic in nature. Perforations in inclined obstacles (baffles) create a multiple jet impingement condition and thus create a situation where all three major heat transfer coefficient enhancement techniques work in unison. The heat transfer augmentation and friction factor in ribbed ducts have been investigated by many researchers [1-7]. Generally, the increased heat transfer rate is accompanied by an increase in friction factor. Thus, engineers or designers have been trying to optimize the rib geometry to yield a best heat transfer coefficient for either a given coolant flow rate or an available pressure drop. The perforated roughness geometry will yield desired heat transfer augmentation with a minimum friction factor. The effect of the perforated ribs on the heat transfer and friction factor have been studied by several investigators [8-12].

In the past, results were published with repeated baffle plates perpendicular to the flow direction. Webb and Ramadhyani [13] studied numerically the laminar fluid flow and heat transfer for a constant property fluid flowing through a parallel channel with staggered transverse baffles and a constant heat flux along both walls. Computations were carried out in the fully-developed regime for different Reynolds numbers, Prandtl numbers, and geometric arrangements. Kelker and Patanker [14] analyzed the flow and heat transfer in two dimensional baffled passage for constant property laminar flow. The passage was formed by two parallel plates to which fins were attached in a staggered fashion. Both the plates were maintained at a constant temperature. Computations were performed for different values of the Reynolds number, PrandtI number, geometric parameters, and the fin-conductance parameter. Calculations were not performed for higher Reynolds number. The results indicate that when the Prandtl number is low, it is found that the use of short fins may indeed decrease the heat transfer. Wang et al. [15] investigated the enhancement of heat transfer due to unsteady flow in channels with in-line and staggered baffles. For this study the geometrical parameters were baffle height to channel height of 0.25 , and baffle spacing to channel height of 1.5 . The Nusselt number increases with Reynolds number, but the rate of growth decreases with increasing Reynolds number. The inline baffle configuration appears to provide a slightly larger Nusselt number than the staggered case at same Reynolds number. Also, the associated friction factors are nearly the same. Habib et al. [16] used the standard $k-\varepsilon$ turbulence model to compute the turbulent flow and heat transfer in a channel with segmented, staggered baffles. It was found that augmentation of heat transfer was obtained with increases 
in the Reynolds number and baffle height and with decreases in baffle spacing. Substantial increases in heat transfer were observed for high Prandtl number fluids. The turbulent flow pattern and heat transfer over staggered baffles of different baffle spacings inside a rectangular channel were described experimentally by Habib et al. [17]. Baffle spacing ranged from 0.8 to 2.0 times the channel height for baffle height to channel height of 0.7 . The investigated Reynolds number ranged from 8000 to 18000. The experimental study by Mobarak et al. [18] and Habib et al. [19] of the flow and heat transfer across segmental baffles indicates significant effect of baffle height and baffle material inside a rectangular duct on the flow pattern, heat transfer, and pressure drop for a fixed baffle spacing. Augmentation of heat transfer was obtained with increase in the Reynolds number, thermal conductivity of baffle, and baffle height. Founti and Whitelaw [20] measured the flow on the shell side of a model disc-and-doughnut baffles heat exchanger. Recently an experimental study by Afify and Abd-Elghany [21] was carried out to provide a detailed investigation of the turbulent flow and heat transfer in a circular pipe with doughnut-and-disc baffles at uniform wall heat flux condition. The experimental runs were carried out for different values of Reynolds number and baffle spacing ratios.

All of the previously mentioned studies have been carried out using the repeated (multiple) perpendicular obstacles with obstacle length to channel height ratio $(\mathrm{L} / \mathrm{H})$ less than 1.0. But these works mainly emphasized on solid obstacles that were perpendicular to the flow direction and for that reason penalties (friction factor) were higher than the improvement (heat transfer augmentation). Unlike previous publications, in this paper experimental analysis of heat transfer enhancement and friction factor are presented with different inclined perforated obstacles to achieve optimum gap between obstacle and upper surface, and perforation condition for $\mathrm{L} / \mathrm{H}$ $>1.0$. It is also of interest, to obtain correlations for both the heat transfer coefficient and flow friction for the present obstacle configurations.

\section{TEST RIG AND MEASURING INSTRUMENTS}

A schematic of the test rig is shown in Fig. 1. The test section is $1200 \mathrm{~mm}$ long and has a rectangular cross section of $50 \times 250 \mathrm{~mm}$ which yields an aspect ratio 1:5. All measurements are done along the centerline of the rectangular channel. Geometrical results are presented in terms of the channel height $(H=50 \mathrm{~mm})$, whereas, heat transfer and friction factors are presented in terms of channel hydraulic diameter $\left(D_{h}=83.3 \mathrm{~mm}\right)$. The details of the test duct section are shown in Fig. 2. Heat is supplied to the test section through only the principle bottom wall while the other three walls are unheated and well insulated. The heat transferring wall (bottom wall) is made of aluminum plates of $5 \mathrm{~mm}$ thickness. The bottom wall plate is heated by electric heaters. The main heater is formed by winding Nickelchromium wires uniformly around a thin mica sheet and sandwiched between another two mica sheets and then inserted between the aluminum plate and asbestos plate. Another similar heater, which worked as a guard heater, is sandwiched between the asbestos plate and the wooden base (20 mm thickness) to minimize the heat loss from the backside of the heated plate. The whole system is tightly fastened with through bolts to ensure good contact. The electric power input 
to the main and guard heaters can be controlled individually by a voltage regulator, which provided a controllable constant heat flux. Figure 2 gives the position of obstacle in the test section along with necessary details and shows view of perforated obstacle. Twenty different obstacle plates of the same width of $25 \mathrm{~mm}$ and thickness of $5 \mathrm{~mm}$ but with different lengths and perforations are used. Leading edges of these baffles are kept sharp to reduce possible flow disturbance by the protruding edge and drilled holes (perforations) through these obstacles create jet impingement effects. All these perforated obstacles have a fixed hole diameter of 10 $\mathrm{mm}$ and hole-center to hole-center spacing is varied from obstacle to obstacle. A row of impingement holes is placed along the centerline of the perforated obstacle to match the thermocouple locations. The obstacle lengths of $100,150,200$, and 300 $\mathrm{mm}$ are used to give obstacle length ratios $(\mathrm{L} / \mathrm{H})$ of $2.0,3.0,4.0$, and 6.0. For each obstacle with same length, the obstacle open-area ratio $(\beta)$ of $0,0.023,0.038,0.115$, and 0.167 are made. The obstacle open-area ratio is defined as:

$$
\beta=\frac{n \pi \phi^{2}}{W L}
$$

where $\mathrm{n}$ is the number of the holes drilled through the perforated obstacle, $\phi$ the radius of the hole, $W$ the width of the channel, and $L$ the obstacle length. Also, the gap between obstacle and upper surface ratios $(B / H)$ of $0.3,0.4,0.55$, and 0.7 are used. A gap of $3 \mathrm{~mm}$ between the bottom heated wall and the obstacle is maintained to avoid flow stagnation at the obstacle plate contact.

The air-flow rate was obtained by a calibrated orifice-meter. Two pressure taps at centerline were located just upstream and downstream of the test section to measure the pressure drop along the test section. The pressure drop across the orifice-meter and the test section were measured by a micromanometer. The pressure drop of the present work is based on adiabatic conditions (without heating). The surface temperatures of heated surface were measured using calibrated copper-constantan thermocouples whose wire diameter was $0.25 \mathrm{~mm}$. The thermocouples were fixed to the back surface of bottom wall and distributed along the centerline of the test section. Thermocouples, which could be traversed vertically, are used to measure the bulk mean air temperature entering and leaving the test section. Bulk temperatures at all other thermocouple locations were calculated from an energy balance. There were two turbulators of $7.0 \mathrm{~mm}$ diameter, one at the inlet and the other at the outlet, to ensure turbulent boundary layer and good mixing of the bulk flow for bulk temperature measurements.

\section{CALCULATION PROCEDURE AND UNCERTAINTY ANALYSIS}

The mass flow rate was set at a desired value. The friction factor (f) was calculated from the pressure drop along the channel axis as:

$$
f=\left[-(\Delta P / \Delta X) \cdot D_{h}\right] /\left(\rho U_{b}^{2} / 2\right)
$$


In this expression, $\Delta \mathrm{P} / \Delta \mathrm{X}$ is an axial pressure gradient, which is evaluated by taking the ratio of the pressure difference and the distance of two successive pressure taps.

After steady state was achieved, the thermocouples readings were recorded. The power input $(Q)$ to the heaters was computed from the measurements of the voltage and resistance of the main heater and then the heat flux (q) calculated.

$$
q=\frac{\left(Q-Q_{\text {loss }}\right)}{A}
$$

The local heat transfer coefficient $\left(h_{x}\right)$ and the corresponding local Nusselt number $(\mathrm{Nu})$ based on the equivalent hydraulic diameter $\left(D_{h}\right)$ were calculated, respectively, as follows:

$$
h_{x}=\frac{q}{\left(T_{w, x}-T_{b, x}\right)}
$$

and

$$
\mathrm{Nu}_{\mathrm{x}}=\frac{\mathrm{h}_{\mathrm{x}} \mathrm{D}_{\mathrm{h}}}{\mathrm{K}}
$$

where $A, T_{w, x}$ and $T_{b, x}$ are the surface area of the heated wall, the wall temperature and the bulk air temperature, receptively. The average Nusselt number $(\mathrm{Nu})$ was calculated from the arithmetic average of all local Nusselt numbers. Also, the Reynolds number based on the equivalent hydraulic diameter was calculated as:

$$
\operatorname{Re}=\frac{U_{b} D_{h}}{v}
$$

where $U_{b}$ is the air-flow mean velocity.

The thermo-physical air properties (e.g. density, specific heat, kinematic viscosity, and thermal conductivity) are based on the mean film temperature.

An uncertainty analysis was performed for evaluation of the accuracy of the experimental measurements. The uncertainty of $\pm 3.7 \%$ was found in calculating the flow Reynolds number. The maximum uncertainty of friction factor was estimated to be less than $\pm 6.2 \%$. The maximum uncertainty in the Nusselt number was $\pm 4.8 \%$.

\section{RESULTS AND DISCUSSION}

The heat transfer and friction factor characteristics are presented. The present measurements cover the cases of different open-area ratios $(\beta=0,0.023,0.038$, 0.115 , and 0.167$)$, different obstacle length to channel height ratios $(\mathrm{L} / \mathrm{H}=2.0,3.0$, 4.0 , and 6.0$)$, gap to channel height ratios $(B / H=0.3,0.4,0.55$, and 0.7$)$ for a range of Reynolds number from 15000 up to 45000. 


\section{Local Heat Transfer Results}

A preliminary series of experiments for the heat transfer coefficient of a smooth channel was conducted to check the accuracy of the experimental set-up and the method of calculations. The present results of the local Nusselt number for smooth duct flow at different Reynolds numbers are shown in Fig. 3.

An evaluation of the heat transfer enhancement achieved by obstacle may be made by comparing the heat transfer characteristics of smooth channel. Figure 4 presents the local Nusselt number distribution at the centerline of the channel for solid obstacle, i.e. without perforations. Figure 4 shows that these obstacle plates deflect the bulk flow away from the heated surface, and the peak occurs at the downstream of the obstacle due to flow reattachment. Figure 4-a shows the variation of the local Nusselt number with the dimensionless distance $\mathrm{x} / \mathrm{H}$ for different Reynolds numbers for obstacle with $\mathrm{L} / \mathrm{H}=4.0$ and $\mathrm{B} / \mathrm{H}=0.4$. The above phenomena appear for all Reynolds numbers. The local Nusselt number values increase with increasing the Reynolds number with same order of magnitude as the smooth channel values, as shown in Fig. 3. In case of $\mathrm{B} / \mathrm{H}=0.4$, the short obstacle is at a steeper angle of attack. Results indicate that obstacle with $\mathrm{L} / \mathrm{H}=2.0$ has a higher peak, and it occurs at an upstream location compared to that of obstacle with $\mathrm{L} / \mathrm{H}=6.0$, the as shown in Fig. 4-b. The effect of the gap ratio, $\mathrm{B} / \mathrm{H}$, with $\mathrm{L} / \mathrm{H}=2.0$ and $\mathrm{Re}=33900$ on the local Nusselt number is shown in Fig. 4-c. Higher values for the local Nusselt number is found for small gap ratio.

Figure 5 illustrates centerline Nusselt number distribution for perforated obstacles. It is clear that the heat transfer characteristics of these perforated obstacles is completely different from those of the solid obstacles. The local Nusselt number is high at the start of the heating section due to the development of the thermal boundary layer. Obstacle insertion at the beginning of the heated section disturbs the boundary layer formation and significant heat transfer coefficient enhancement is noted. Local peaks are due to the jet impingement effect and these multiple impinging jets develop a highly turbulent cross flow that also enhances the heat transfer coefficient. Near the trailing end of the obstacle, jet enhanced turbulent mixing becomes weak due to a divergent orientation of the obstacle that results in a decrease of the Nusselt nurnber. The downward trend of Nusselt continues until the end of the obstacle. Immediately after the baffle, the heat transfer coefficient increases by the by-passed flow that does not participate in impingement and further downstream the heat transfer behavior approaches a smooth channel condition.

The variation of local Nusselt number at different Reynolds numbers for $L / H=4.0$, $B / H=0.4$, and $\beta=0.023$ is shown in Fig. 5-a. The effect of the perforation (perforated obstacle open-area ratio, $\beta$ ) for obstacles with $\mathrm{L} / \mathrm{H}=6.0, \mathrm{~B} / \mathrm{H}=0.4$, and $\mathrm{Re}=44600$ on the local Nusselt number is shown in Fig. 5-b. An interesting observation is that Nusselt numbers are mostly higher for a obstacle of less perforation density. At low perforation or fewer number of holes, an enhancement of heat transfer coefficient obtained by obstacle may be due to the fact that cross flow by spent jets is stronger for more perforated obstacle and that reduces impingement effect. Moreover, due to higher flow resistance in obstacle of less perforation density $(\beta=0.023)$, more air passes through the gap between the obstacle and the upper surface; and that increase the reattachment heat transfer coefficient. It is interesting to note that the perforation density significantly affects the location of the 
reattachment heat transfer enhancement. The reattachment zone occurs early in less perforated obstacle than that of more perforated obstacle. It can be argued that flow passing through impingement chamber is stronger in more perforated obstacle and as a result the by-pass flow is weaker and thus reattachment is delayed. The influence of the obstacle length ratio $(\mathrm{L} / \mathrm{H})$ on the centerline local Nusselt number is shown in Fig. 5-c for obstacles with $\mathrm{B} / \mathrm{H}=0.4, \beta=0.023$, and $\mathrm{Re}=22700$. This figure shows the secondary peak (due to reattachment) in local Nusselt number distribution occurs early with decreasing the length ratio at the downstream of the obstacle and a longer uniform Nusselt number results at downstream due to a shorter region of disturbance. Figure 5-d illustrates centerline Nusselt number distribution for obstacle with $\mathrm{L} / \mathrm{H}=6.0, \beta=0.023$, and $\mathrm{Re}=33900$ at different gap ratios $(B / H)$. As shown in Fig. 5-d, the performance of baffle obstacles deteriorates with the increase in gap ratio, $\mathrm{B} / \mathrm{H}$. A lower gap ratio shows higher Nusselt number for same obstacle length and perforation density and there are two possible explanations for this observation. The first explanation is, as the gap increases, the obstacle becomes almost flat and fails to provide jet impingement due to a lowpressure difference across the jet holes; and the second explanation is, in case of a higher gap, a weaker reattachment is expected.

\section{Average Heat Transfer and Friction Results}

The variation of the average Nusselt number and the friction factor with Reynolds number for the smooth channel is shown in Fig. 6 . The present results of average Nusselt number for the smooth channel were compared with some previous correlations of Dittus and Boelter and Gnielinski correlations listed in Mills [22], $\mathrm{Nu}_{\mathrm{o}}=0.023 \mathrm{Re}^{0.8} \mathrm{Pr}^{0.4}$. Also, the friction factor results were compared with Petukhov correlation listed in Mills [22] and Blasius correlation listed in Liou and Chen [12], $f_{o}=0.316 \operatorname{Re}^{-0.25}$. Excellent agreements were found as shown in Fig. 6 .

The heat transfer coefficient is presented here in terms of the ratio of Nusselt number for the channel with obstacle to those for the smooth one. These Nusselt number ratios $\left(\mathrm{Nu} / \mathrm{Nu}_{0}\right)$ indicate the amount of improvement in heat transfer coefficient obtained by these obstacles over a fully developed smooth channel condition. Also, the friction factor ( $f$ ) of the present study is normalized by the friction factor for the smooth channel $\left(f_{0}\right)$.

The results indicate that the Nusselt number enhancement and friction factor ratios are independent of the value of Reynolds number as shown in Fig. 7. The heat transfer enhancement and friction factor ratios increase with decrease in the obstacle open-area ratio and gap ratio. As shown in Fig. 7-b, the average Nusselt number mostly stays the same with different Reynolds numbers but the friction factor ratio increases with decreasing the obstacle length. The result showed that the maximum heat transfer enhancement and friction factor were about 3.7 and 11.0 times more than that of smooth channel, respectively, and these values were achieved using obstacle with $\beta=0.023, \mathrm{~L} / \mathrm{H}=2.0$, and $\mathrm{B} / \mathrm{H}=0.3$.

Also, to better illuminate the flow and heat transfer characteristics, the efficiency index $(\eta)$ which is defined by the ratio between the Stanton number enhancement 
ratio to friction factor ratio, was calculated as $\eta=\left(\mathrm{St} / \mathrm{St} \mathrm{t}_{0}\right) /\left(\mathrm{f} / \mathrm{f}_{\mathrm{o}}\right)=\left(\mathrm{Nu} / \mathrm{Nu}_{0}\right) /\left(\mathrm{f} / \mathrm{f}_{\mathrm{o}}\right)$ and plotted against the Reynolds number and gap ratio at different obstacle geometries as shown in Fig. 8. The inclined perforated obstacle with can provide greater efficiency index than ribbed channel [6] and baffled channel with multiple baffles at different baffle spacing to pipe diameter ratio (S/D) [21], as shown in Fig. 8-a. The efficiency index increases with increase in perforation density, obstacle length, and gap ratio. The greatest efficiency index was found for the obstacle with $\beta=0.167$, $\mathrm{L} / \mathrm{H}=6.0$, and $\mathrm{B} / \mathrm{H}=0.7$, where, a maximum efficiency index of about 1.6 is found as shown in Fig. 9.

Moreover, the centerline Nusselt number enhancement ratio $\left(\mathrm{Nu} / \mathrm{Nu}_{0}\right)$ was correlated as a function of gap ratio and open-area of perforated obstacle as follows:

$$
\mathrm{Nu} / \mathrm{Nu}_{\mathrm{o}}=1.18(\mathrm{~B} / \mathrm{H})^{-0.75}+0.11 \beta^{-0.52}
$$

Also, the values of the friction factor ratio $\left(f / f_{0}\right)$ were correlated in terms of obstacle length ratio, gap ratio and open-area of perforated obstacle and the following correlation was obtained:

$$
\mathrm{f} / \mathrm{f}_{\mathrm{o}}=1.26(\mathrm{~L} / \mathrm{H})^{-0.27}(\mathrm{~B} / \mathrm{H})^{-2.0}(1+\beta)^{-2.2}
$$

The heat transfer and friction correlations given above are valid for a single inclined perforated obstacle in a rectangular channel with the parameters ranges $15000 \leq \operatorname{Re} \leq 45000,0.023 \leq \beta \leq 0.167,2.0 \leq \mathrm{L} / \mathrm{H} \leq 6$, and $0.3 \leq \mathrm{B} / \mathrm{H} \leq 0.7$. These correlations were valid with a maximum deviation of $\pm 5 \%$, as shown in Fig. 9. These correlations may be useful in the design of related devices such as gas turbine blade cooling channels, air-cooled solar collectors, electric cooling packages, heat exchangers, and power plants.

\section{CONCLUSIONS}

An experimental study was presented to provide a detailed investigation of the frictional loss and heat transfer characteristics in a rectangular channel with single inclined perforated obstacle at a uniform wall heat flux condition. The experimental runs were carried out for different values of Reynolds number, perforated obstacle open-area (perforation), obstacle length, and gap between obstacle and upper surface. Inclined perforated obstacle combines three major heat transfer techniques, e.g. boundary layer separation, internal flow swirls, and jet impingement. The main conclusions of the present study are as follows:

1. The Results indicate that perforated obstacle improves heat transfer coefficient compared to a similar dimension solid obstacle for this favorable configuration.

2. The perforated obstacles having moderate perforation is better for channel centerline heat transfer than those of densely perforated obstacles of the same overall dimension. Also, the local Nusselt numbers is significantly dependent on the gap ratio and the Nusselt number decreases as the plate is placed at a more streamlined position or gap ratio. 
3. Both the heat transfer enhancement ratio and the friction factor ratio are independent of the value of Reynolds number.

4. The Nusselt number enhancement ratio $\left(\mathrm{Nu} / \mathrm{Nu}_{0}\right)$ increases with decrease in perforation density (open-area ratio), and gap between obstacle and upper surface. Also, the Nusselt number enhancement ratio mostly stays the same with different obstacle lengths.

5. The friction factor ratio $\left(f / f_{0}\right)$ decreases with increase in perforation density, obstacle length, and gap ratio.

6. The maximum heat transfer enhancement and friction factor were about 3.7 and 11.0 times more than that smooth channel, respectively, and these values were achieved using obstacle with $\beta=0.023, \mathrm{~L} / \mathrm{H}=2.0$, and $\mathrm{B} / \mathrm{H}=0.3$.

7. The inclined perforated obstacle with can provides greater efficiency index than ribbed channel and baffled channel with multiple baffles.

8. The greatest efficiency index was found for the obstacle with $\beta=0.167, \mathrm{~L} / \mathrm{H}=6.0$, and $\mathrm{B} / \mathrm{H}=0.7$, where, a maximum efficiency index of about 1.6 is found.

9. New empirical correlations for average centerline Nusselt number enhancement ratio and friction factor ratio were obtained.

\section{REFERENCES}

1. Zhang, Y. M., Gu, W. Z., and Han, J. C., "Heat Transfer and Friction in Rectangular Channels with Ribbed or Ribbed-Grooved Walls," ASME Journal of Heat Transfer, Vol. 116, pp. 58-65, (1994).

2. Liou, T. M., Wang, W. B., and Chang, Y. J., "Holographic Interferometry Study of Spatially Periodic Heat Transfer in a Channel with Ribs Detached From one Wall," ASME Journal of Heat Transfer, Vol. 117, pp. 32-39, (1995).

3. Hwang, J. J., "Heat Transfer-Friction Characteristic Comparison in Rectangular Ducts with Slit and Solid Ribs Mounted on one Wall," ASME Journal of Heat Transfer, Vol. 120, pp. 709-716, (1998).

4. Yung, T. J., and Vafai, K., "Experimental and Numerical Investigation of Forced Convection Characteristics of Arrays of Channel Mounted Obstacles," ASME Journal of Heat Transfer, Vol. 121, pp. 34-42, (1999).

5. Hanafi, A. S., El-Shazly, K. M., and Abdel-Aziz, A. A., "Heat Transfer Characteristics and Velocity Measurements of Main Flow in A Rectangular Channel With Two Ribbed-Walls," Proceedings of Al-Azhar Engineering Sixth International Conference, Vol. 7, September 2000, Cairo, Egypt, pp. 269-288, (2000).

6. Atwan, E. F., El-Shamy, A. R., and Abdel-Moneim, S. A., "Heat Transfer Enhancement Using Repeated Zigzag Ribs Affixed on the Bottom Wall of a Rectangular Channel," Journal of Engineering Research, El Mattaria Faculty of Eng., Cairo, Egypt, Vol. 72, pp. 39-54, (2000).

7. Afify, R. I., "Turbulent Flow and Heat Transfer Past an Array of Ribs Aligned with Different Heights and Pitches Along Channel Axis," Proceedings of the $8^{\text {th }}$ International Conference on Energy and Environment, Jan. 4-7, 2003, Cairo, Egypt, (2003). 
8. Hwang, J. J., and Liou T. M., "Augmented Heat Transfer in a Rectangular Channel with Permeable Ribs Mounted on the Wall," ASME Journal of Heat Transfer, Vol. 116 , pp. 912-920, (1994).

9. Hwang, J. J., and Liou, T. M., "Heat Transfer and Friction in a Low-Aspect-Ratio Rectangular Channel with Staggered Perforated Ribs on Two Opposite Walls," ASME Journal of Heat Transfer, Vol. 117, pp. 843-850, (1995).

10.Liou, T. M., Kao, C. W., and Chen, S. H., "Flowfield Investigation of the Effect of Rib Open Area Ratio in a Rectangular Duct," ASME Journal of Heat Transfer, Vol. 120 , pp. 504-512, (1998).

11.Hwang, J. J., Yulia T., and Liou, T. M., "Effect of Fence thickness on Pressure Drop and Heat Transfer in a Perforated-Fenced Channel," Int. Journal of Heat and Mass Transfer, Vol. 41, Nos. 4-5, pp. 811-816, (1998).

12.Liou, T. M., and Chen S. H., "Turbulent Heat and Fluid Flow in a Passage Disturbed by Detached Perforated Ribs of Different Heights," Int. Journal of Heat and Mass Transfer, Vol. 41, No. 12, pp. 1795-1806, (1998).

13.Webb, B. W. and Ramadhyani, S., "Conjugate Heat Transfer in a Channel with Staggered Ribs," Int. J. Heat Mass Transfer, Vol. 28, No. 9, pp. 1679-1687, (1985)

14.Kelkar, K. M. and Patankar, S. V., "Numerical Prediction of Flow and Heat Transfer in a Parallel Plate Channel with Staggered Fins," ASME Journal of Heat Transfer, Vol. 109, pp. 25-30, (1987).

15.Wang, G., Stone, K. and Vanka, S. P., "Unsteady Heat Transfer in Baffled Channel," ASME Journal of Heat Transfer, Vol. 118, pp. 585-591, (1996).

16. Habib, M. A., Attya, A. E., and McEligot, D. M., "Calculation of Turbulent Flow and Heat Transfer in Channels with Streamwise-Periodic Flow," ASME Journal of Turbomachinery, Vol. 110, pp. 405-411, (1988).

17. Habib, M. A., Mobarak, A. M., Attya, A. M., and Aly, A. Z., "Enhanced Heat Transfer in Channels with Staggered Fins of Different Spacings," Int. J. Heat and Fluid Flow, Vol. 14, No. 2, pp. 185-190, (1993).

18.Mobarak, A. M., Habib, M. A., Abdel Hadi, E. A., Sallak, M. A., and Afify, R. I., "Turbulent Flow and Heat Transfer in Rectangular Duct With Segmental Baffles of Different Heights," Journal Helwan Univ., Vol. 1, pp. 1-12, (1991).

19. Habib, M. A., Mobarak, A. M., Sallak, M. A., Abdel Hadi, E. A., and Afify, R. I., "Experimental Investigation of Heat Transfer and Flow Over Baffles of Different Heights," ASME Journal of Heat Transfer, Vol. 116, pp. 363-368, (1994).

20.Founti, M. A., and Whitelaw, J. H., "Shell-Side Flow in a Model Disc-andDoughnut Heat Exchanger," Tech. Report FS/81/37, Mech. Eng. Dept., Imperial College, London, United Kingdom, (1981).

21.Afify, R. I. and Abd-Elghany, M. E., "Turbulence and Heat Transfer Measurements Over Doughnut-and-Disc Baffles in Circular Pipe," Journal of Engineering Research, El Mattaria Faculty of Eng., Cairo, Egypt, Vol. 52, pp. 120, (1997).

22.Mills, A. F., Heat Transfer, Prentice-Hall, Inc., Upper Saddle River, New Jersey, (1999) 


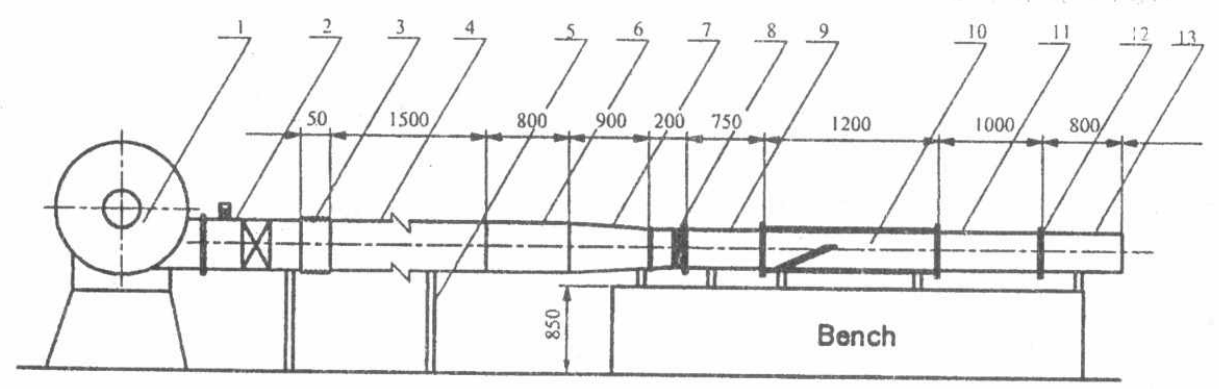

1- Air blower

2- By-pass sec.

6- Diffuser sec.

7- Converging sec.

10- Test sec.

3- Rubber sec.

8- Hony comb sec.

11- First segment of orifice meter

4- P.V.C. tube sec.

9- Straight duct

12- Orifice meter plate

13- Second segment of orifice meter

5- Supports

Fig. 1 Experimental set-up

Dims. in $\mathrm{mm}$
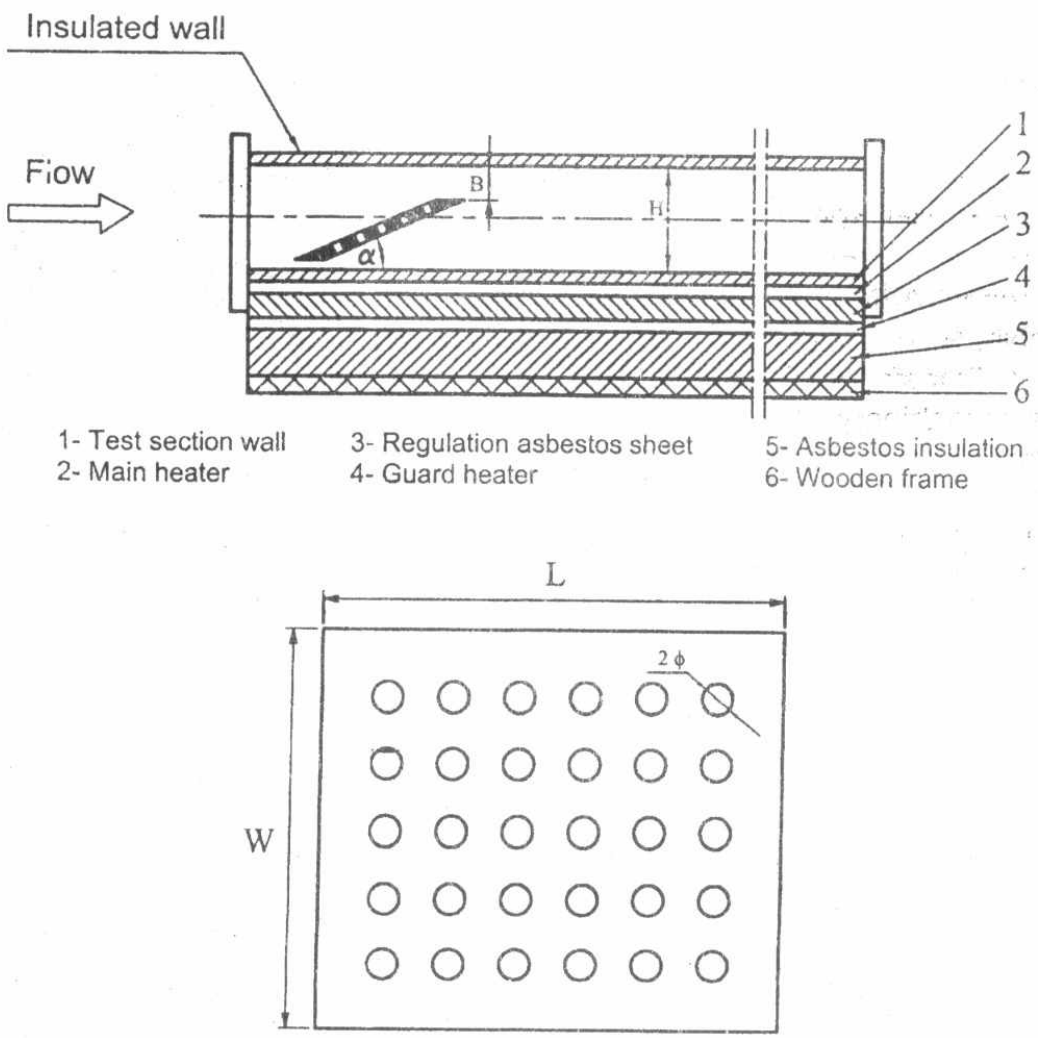

Obstacle plate

Fig. 2 Details of heated test section and obstacle plate 


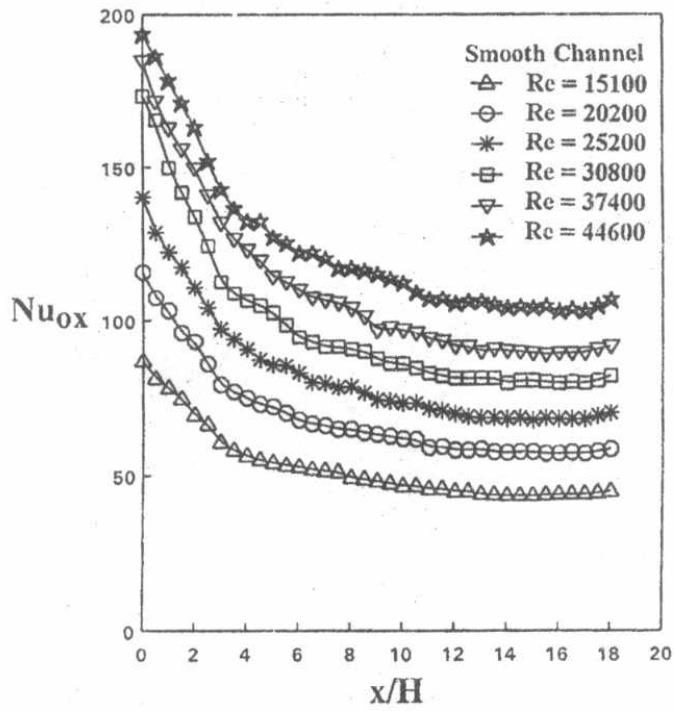

Fig. 3. Distributions of local centerline Nusselt number ( $\left.\mathrm{Nu}_{\mathrm{ox}}\right)$ along the heated wall at different Reynolds numbers for smooth channel.

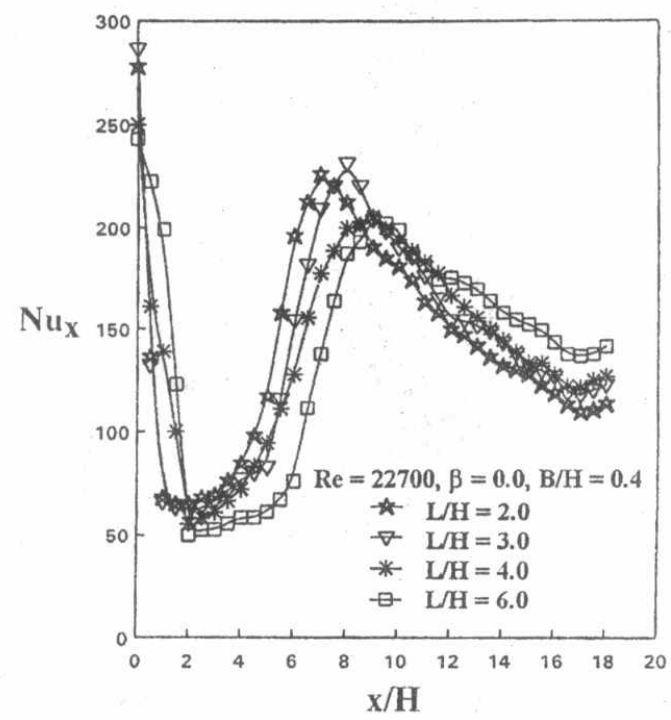

Fig. 4b. $R e=22700$ and $B / H=0.4$ at different obstacle lengths.

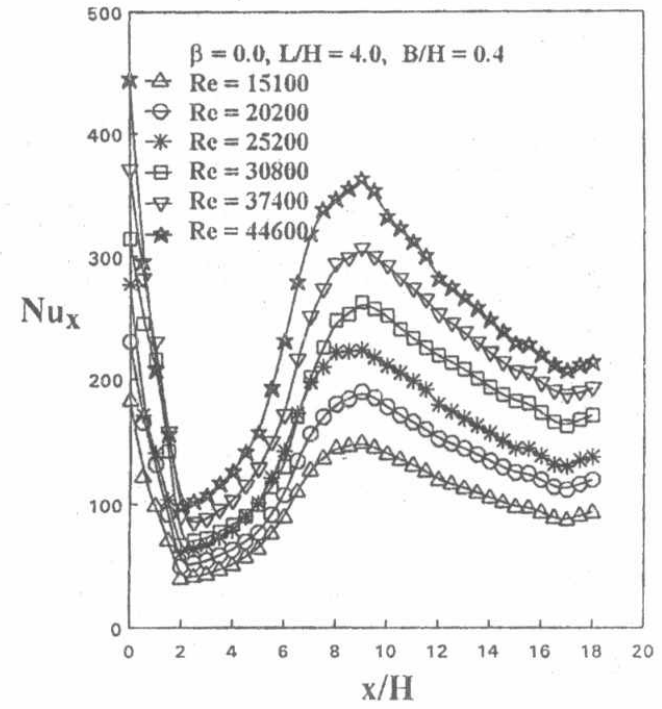

Fig. $4 a$. $L / H=4.0$ and $B / H=0.4$ at different Reynoids numbers.

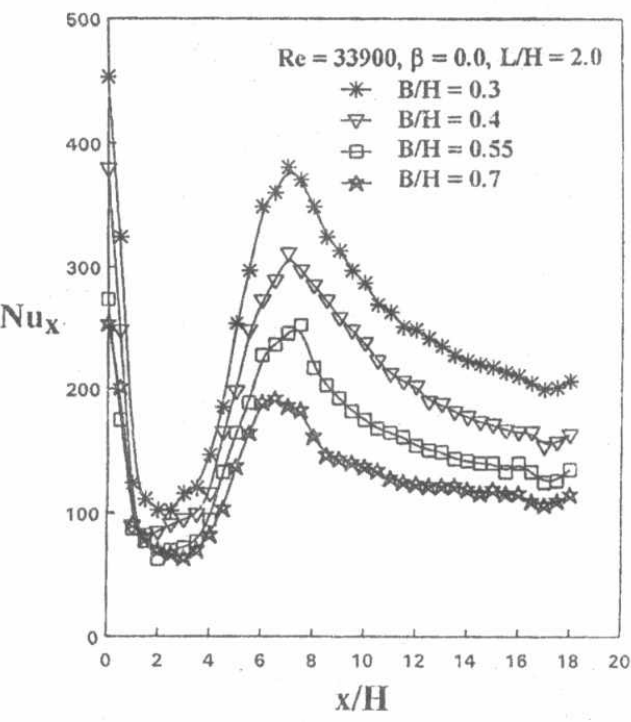

Fig. 4c. $R e=33900$ and $L / H=2.0$ at different gap ratios.

Fig. 4. Distributions of local centerline Nusselt number $\left(\mathrm{Nu}_{\mathrm{x}}\right)$ along the heated wall for channel with solid obstacle plate. 


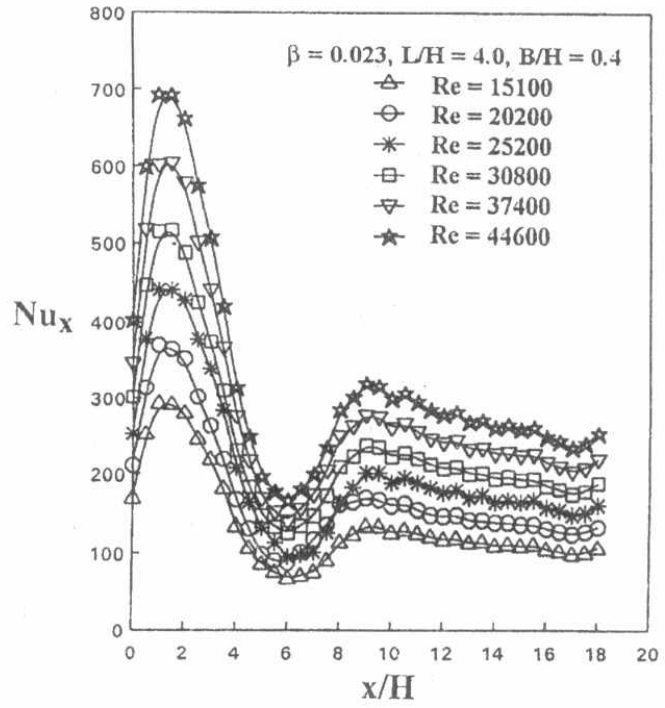

Fig. 5a. $\beta=0.023, \mathrm{~L} / \mathrm{H}=4.0$, and $\mathrm{B} / \mathrm{H}=0.4$ at different Re.

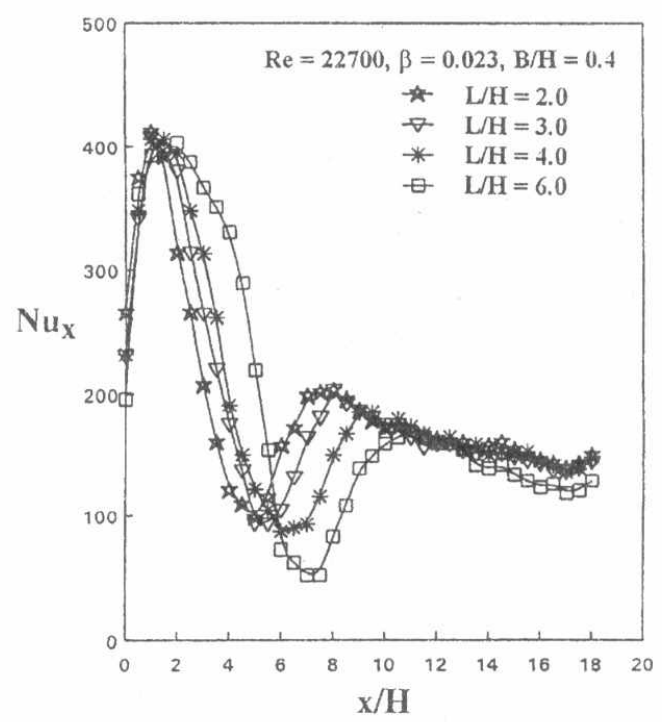

Fig. 5c. $\operatorname{Re}=22700, \beta=0.023$, and $\mathrm{B} / \mathrm{H}=0.4$ at different obstacle lengths.

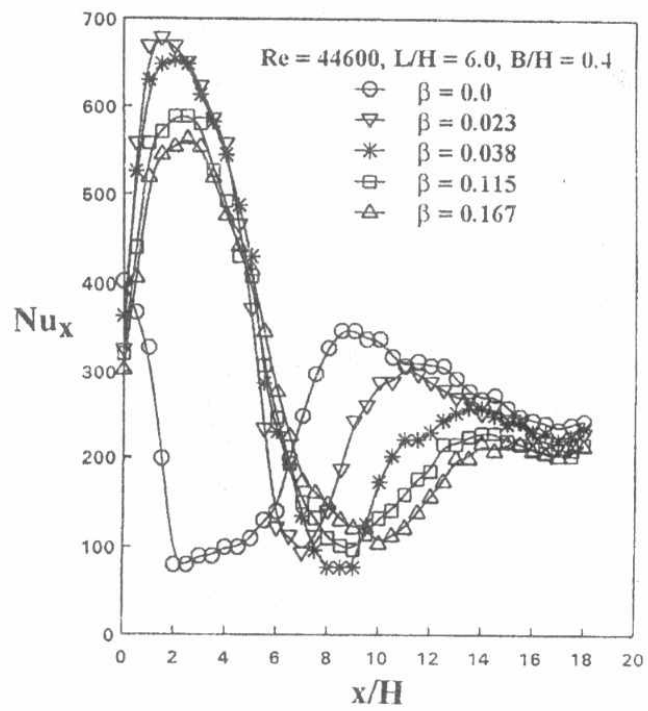

Fig. 5b. $\mathrm{Re}=44600, \mathrm{~L} / \mathrm{H}=6.0$, and $\mathrm{B} / \mathrm{H}=0.4$ at different perforations.

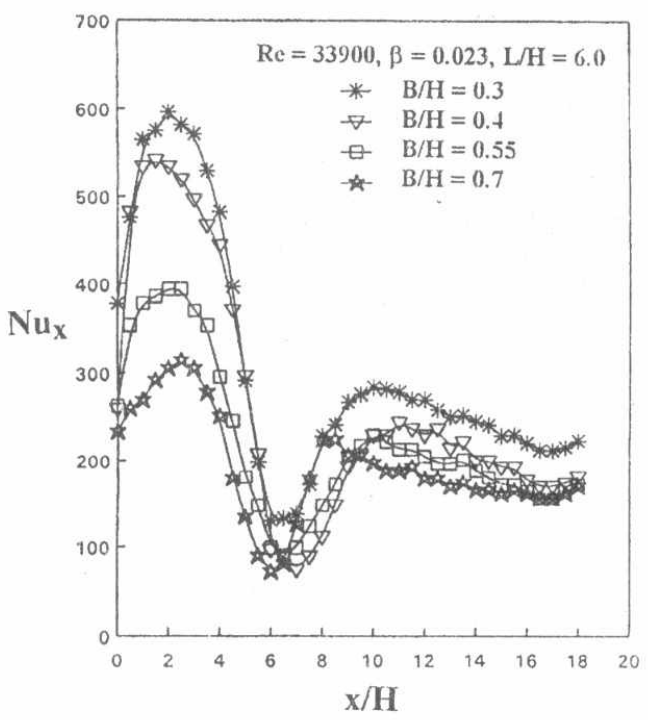

Fig. $5 d$. $\operatorname{Re}=33900, \beta=0.023$, and $\mathrm{L} / \mathrm{H}=6.0$ at different gap ratios.

Fig. 5. Distributions of local Nusseit number $\left(\mathrm{Nu}_{\mathrm{x}}\right)$ along the heated wall for channel with perforated obstacle plate. 

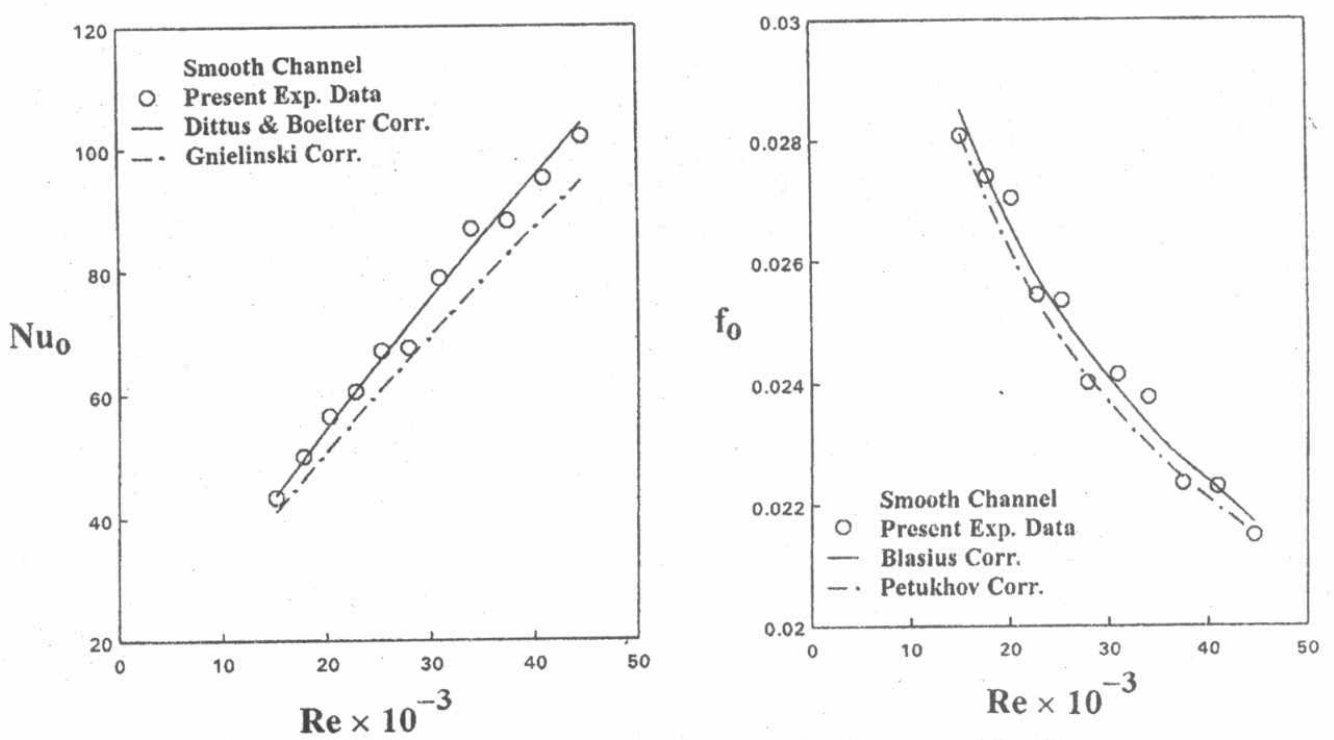

Fig. 6. Average centerline Nusselt number ratio $\left(\mathrm{Nu}_{0}\right)$ and friction factor $\left(\mathrm{f}_{0}\right)$ versus Reynolds number for smooth channel compared with previous published correlations.
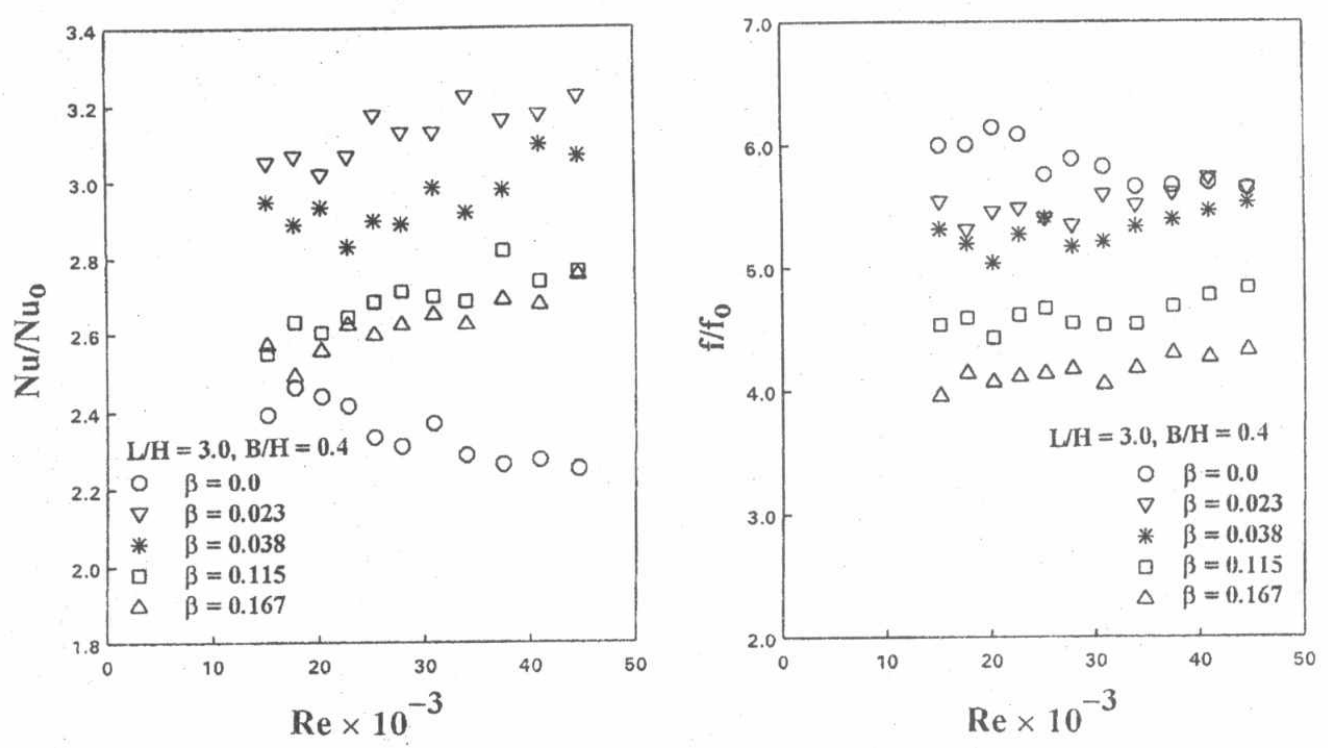

Fig. 7a. $L / H=3.0$, and $B / H=0.4$ at different perforations $(\beta)$.

Fig. 7. Average centerline Nusselt number ratio ( $\left.\mathrm{Nu} / \mathrm{Nu}_{0}\right)$ and friction factor ratio $\left(f / f_{0}\right)$ versus Reynolds number for channel with perforated obstacle plate. 

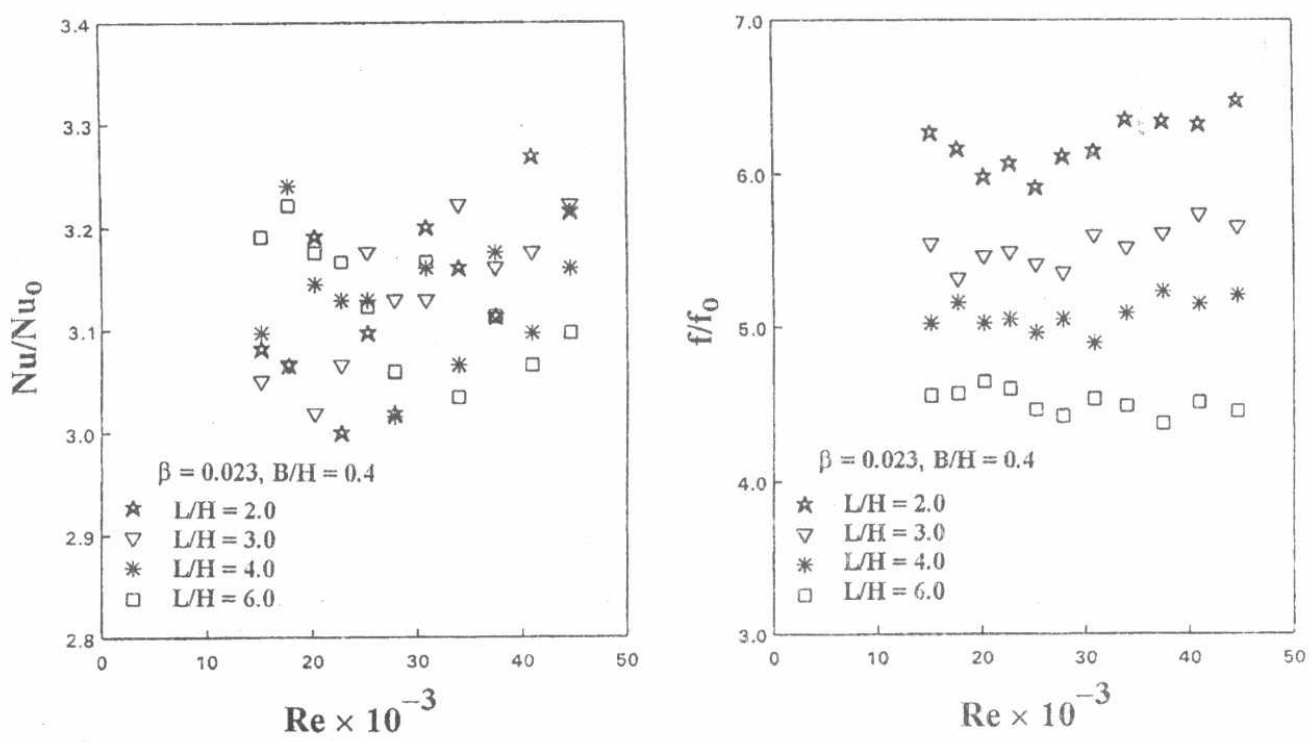

Fig. 7b. $\beta=0.023$, and $B / H=0.4$ at different obstacle lengths.
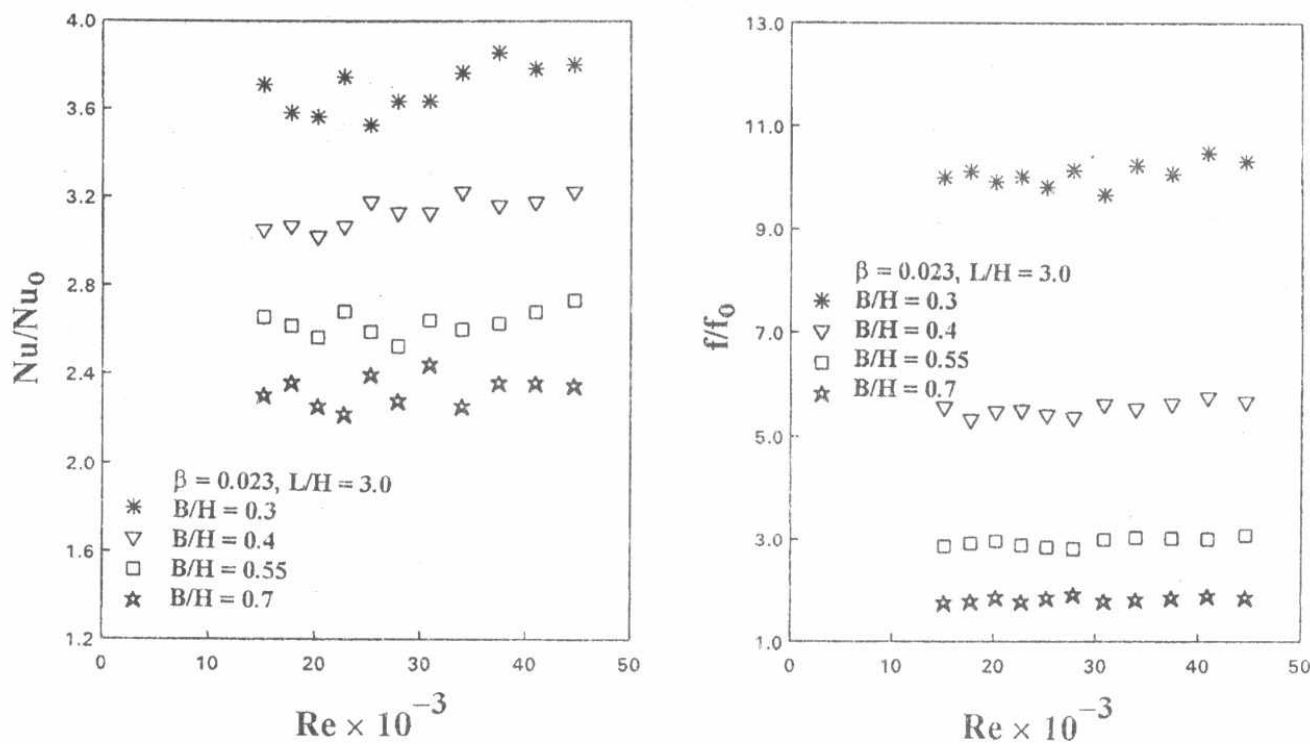

Fig. 7c. $\beta=0.023$, and $L / H=3.0$ at different gap ratios.

Fig. 7. (Continued) 


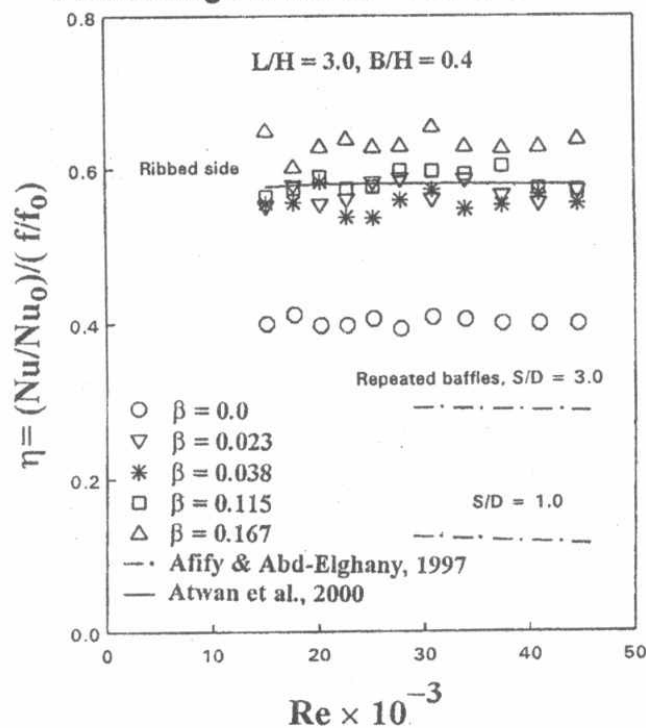

Fig. 8a. $L / H=3.0$, and $B / H=0.4$ at different perforations $(\beta)$.

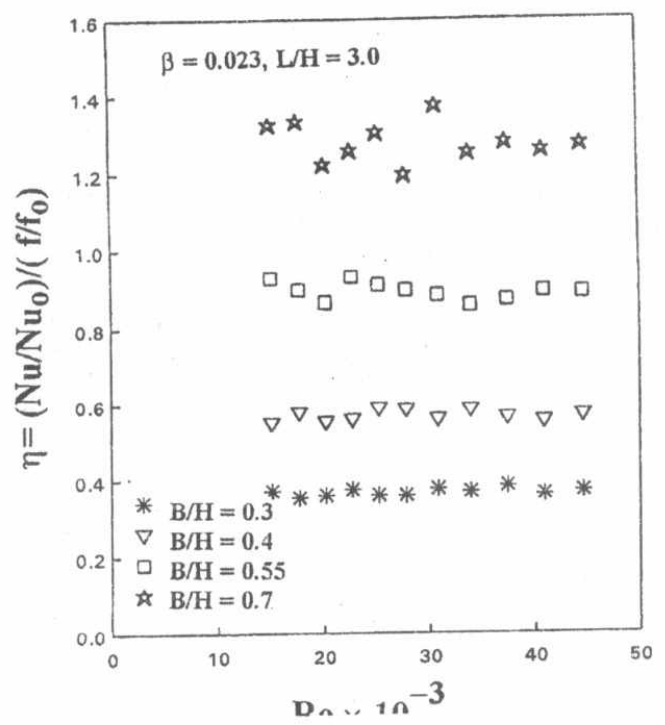

Fig. 8 c. $\beta=0.023$, and $L / H=3.0$ at different gap ratios.

Fig. 8. Efficiency index $(\eta)$ versus Reynolds number for channel with perforated obstacle plate.

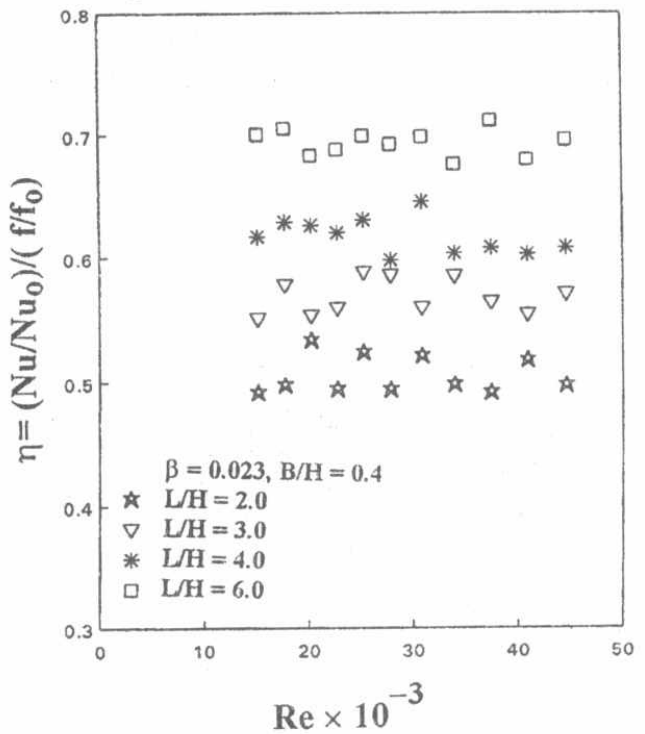

Fig. $8 b . \quad \beta=0.023$, and $B / H=0.4$ at different obstacle lengths.

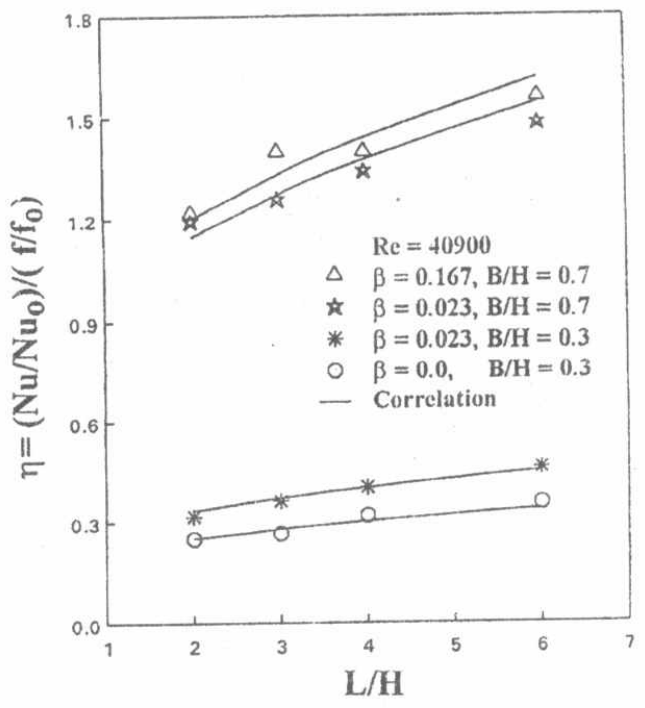

Fig. 9. Efficiency index $(\eta)$ versus obstacle length for channel with perforated obstacle plate. 